\title{
Mechanical ventilation in emergency departments: Non invasive or invasive mechanical ventilation. Where is the answer?
}

\author{
Antonio M Esquinas Rodriguez ${ }^{1 *}$, Roberto Cosentini ${ }^{2}$ and Peter J Papadakos ${ }^{3}$
}

Keywords: Emergency department, Non-invasive mechanical ventilation, Mechanical ventilation, Trauma, Length of stay

\section{Background}

The Emergency Department length of stay for patients requiring mechanical ventilation paper in this issue is very illustrative of many variables that still confound the way we treat patients that may not require endotracheal intubation (ETI) but may benefit from non-invasive mechanical ventilation (NIV) [1].

Rose $\mathrm{L}$ et al. bring to light several important aspects the chief of which is the way we view this modality [1]. Patients that refused endotracheal intubation, but accepted NIV were not clearly identified as to whether this was done as a terminal mode as an end-of-life decision or if this was a bridge to prevent endotracheal intubation and allow pharmacotherapy to improve patient status such as heart failure. Caregiver trends and service battles are clearly illustrated in this study as a large confounder was or which service will care for the patient on the floor, step down or intensive care unit (ICU). With the great pressure to provide proper utilization of staff and technology rich environments, much of the push back to keep patients of NIV in the in the ED may be from the ICU itself. ED staff input is also a key variable leading the delays we found in interesting that only $55.2 \%$ of patients received arterial blood gas following commencement of mechanical ventilation which would be unusual for accepted ICU practice [1]. This lack of follow-up illustrates how patients receiving ventilator support are placed in a holding pattern in the ED and do not get active care input.

\footnotetext{
* Correspondence: antmesquinas@gmail.com

${ }^{1}$ International Fellow AARC, Intensive Care Unit, Hospital Morales Meseguer, Avenida Marques de Los Velez s/n, Murcia 30500, Spain

Full list of author information is available at the end of the article
}

The core pattern illustrated by this study is the reluctance of EDs and ICUs to develop set protocols to care for these patients and provide rapid placement. The trauma data in this study supports this statement in that trauma centers utilize the standards of the advance trauma life support guidelines most meet quality indicators for time to transfer either to the ICU or the operative theater. The other important point is that ED staff may not fully appreciate the status of a patient on NIV [1]. The intubated patient is always considered a patient that requires critical care, thus staff may pressure the ICU to spread transfer $[1,2]$. It would be interesting for these investigators recorded the number of calls made to units by staff.

We believe that many of the delays could be addressed through developments of guidelines or protocols on how we care for both intubated and NIV patients in the emergency department [3,4]. Also, resources such as RT's or specially trained nurses need to be placed in the ED to manage these patients so they do not fall behind in their care. This is an important aspect in providing ideal care, especially in patients where NIV is being used to prevent intubation $[3,4]$. Delays in transfer to units may increase as economic and acuity pressures add to the burdens of the health care system $[5,6]$. So we much address this issue o ventilated patients before it balloons and affects mortality and care indicators.

\section{Abbreviation}

ED: Emergency Department; ETI: Endotracheal intubation; ICU: Intensive Care Unit; NIV: Non-invasive mechanical ventilation.

\section{Competing of interest}

The authors should be congratulated for bringing this data to light. The author(s) declare have no potentially conflicting personal of financial interests. 


\section{Author details}

'International Fellow AARC, Intensive Care Unit, Hospital Morales Meseguer, Avenida Marques de Los Velez s/n, Murcia 30500, Spain. ${ }^{2}$ Gruppo_NIV UO Medicina d'Urgenza, Fondazione Ca' Granda, IRRCS Policlinico Milano, Via Francesco Sforza, 35, Milan, Italy. ${ }^{3}$ Surgery and Neurosurgery, Director Critical Care, University of Rochester, Rochester, NY, USA.

Received: 16 June 2012 Accepted: 17 June 2012

Published: 26 June 2012

\section{References}

1. Rose L, Gray S, Burns K, Atzema C, Kiss A, Worster A, Scales DC, Rubenfeld G, Lee J: Emergency department length of stay for patients requiring mechanical ventilation: a prospective observational study. Scand J Trauma Resusc Emerg Med 2012, 20(1):30.

2. Serviá L, Badia M, Baeza I, Montserrat N, Justes M, Cabré X, Valdrés P Trujillano J: Time spent in the emergency department and mortality rates in severely injured patients admitted to the intensive care unit: An observational study. J Crit Care 2012, 27(1):58-65.

3. Kikuchi T, Toba S, Sekiguchi Y, Iwashita T, Imamura H, Kitamura M, Nitta K, Mochizuki K, Okamoto K: Protocol-based noninvasive positive pressure ventilation for acute respiratory failure. J Anesth 2011, 25(1):42-49.

4. Singh VK, Khanna P, Rao BK, Sharma SC, Gupta R: Outcome predictors for non-invasive positive pressure ventilation in acute respiratory failure. J Assoc Physicians India 2006, 54:361-365.

5. Chalfin DB, Trzeciak S, Likourezos A, Baumann BM, Dellinger RP. DELAY-ED study group. Impact of delayed transfer of critically ill patients from the emergency department to the intensive care unit. Crit Care Med 2007, 35(6):1477-1483

6. Mowery NT, Dougherty SD, Hildreth AN, Holmes JH 4th, Chang MC, Martin RS, Hoth JJ, Meredith JW, Miller PR: Emergency department length of stay is an independent predictor of hospital mortality in trauma activation patients. J Trauma 2011, 70(6):1317-1325.

doi:10.1186/1757-7241-20-40

Cite this article as: Esquinas Rodriguez et al:: Mechanical ventilation in emergency departments: Non invasive or invasive mechanical ventilation. Where is the answer?. Scandinavian Journal of Trauma, Resuscitation and Emergency Medicine 2012 20:40.

\section{Submit your next manuscript to BioMed Central and take full advantage of:}

- Convenient online submission

- Thorough peer review

- No space constraints or color figure charges

- Immediate publication on acceptance

- Inclusion in PubMed, CAS, Scopus and Google Scholar

- Research which is freely available for redistribution 